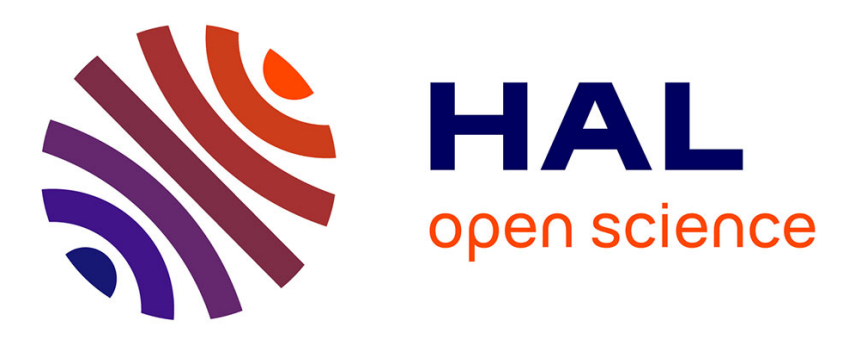

\title{
Facile synthesis of palladium nanowires by a soft templating method
}

Prem Siril, Anaïs Lehoux, Laurence Ramos, Patricia Beaunier, Hynd Remita

\section{To cite this version:}

Prem Siril, Anaïs Lehoux, Laurence Ramos, Patricia Beaunier, Hynd Remita. Facile synthesis of palladium nanowires by a soft templating method. New Journal of Chemistry, 2012, 36 (10), pp.2135. $10.1039 / \mathrm{c} 2 n j 40342 \mathrm{k}$. hal-00760633

\section{HAL Id: hal-00760633 https://hal.science/hal-00760633}

Submitted on 5 Dec 2013

HAL is a multi-disciplinary open access archive for the deposit and dissemination of scientific research documents, whether they are published or not. The documents may come from teaching and research institutions in France or abroad, or from public or private research centers.
L'archive ouverte pluridisciplinaire HAL, est destinée au dépôt et à la diffusion de documents scientifiques de niveau recherche, publiés ou non, émanant des établissements d'enseignement et de recherche français ou étrangers, des laboratoires publics ou privés. 


\title{
Facile synthesis of palladium nanowires by a soft templating method
}

\author{
Prem Felix Siril, $\dagger^{a b}$ Anaïs Lehoux, ${ }^{a b}$ Laurence Ramos, ${ }^{c d}$ Patricia Beaunier ${ }^{e}$ and \\ Hynd Remita $* a b$
}

\author{
Received (in Montpellier, France) 2nd May 2012, Accepted 27th July 2012 \\ DOI: $10.1039 / \mathrm{c} 2 \mathrm{nj} 40342 \mathrm{k}$
}

Very long and thin monocrystalline Pd nanowires were synthesized by decomposition using hydrazine vapour treatment of $\operatorname{Pd}_{2}(\mathrm{DBA})_{3}$ confined in the oil phase of a hexagonal mesophase. The mesophase is composed of toluene-swollen tubes, doped with the Pd precursor, stabilized by a monolayer of surfactant and cosurfactant molecules, and arranged on a triangular lattice in water. Our synthesis is selective and the experiments show that both the confinement and the nature of the surfactant are essential to obtain these Pd nanowires.

\section{Introduction}

The shape- and size-dependent properties of nanoparticles are well established. ${ }^{1-6}$ Synthesis of nanoparticles of controlled morphologies has been explored in order to enhance their performances. ${ }^{7,8}$ One-dimensional metal nanostructures including nanorods and nanowires are attracting much attention because of their unique electrical, optical, magnetic and sensing properties, as well as their potential applications in nanodevices.

Palladium is a versatile catalyst for a large number of industrially important reactions such as hydrogenation of unsaturated organic compounds ${ }^{2,10}$ and a number of important C-C coupling reactions, such as Heck and Suzuki reactions. ${ }^{11-15}$ Palladium nanoparticles show a high catalytic activity for ethanol electrooxidation in basic media and their electroactivity is even higher than that of platinum. ${ }^{16-19}$ Palladium is also a promising material for hydrogen storage and sensing. ${ }^{20-25}$

Palladium nanomaterials were synthesized with different shapes such as triangular and hexagonal nanoplates, ${ }^{26}$ rectangular particles $^{27}$ single crystalline nanothorns ${ }^{28}$, nanosheets ${ }^{2-31}$ and porous nanoballs. ${ }^{32}$ Among other nanostructures palladium nanowires are particularly interesting because of their applications in catalysis and electrocatalysis, hydrogen storage and sensing. ${ }^{19,33,34}$ It has also been shown that ultra-thin (2-3 nm in diameter) palladium nanowires exhibit ferromagnetism down to room temperature whereas bulk palladium is paramagnetic. ${ }^{35,36}$

${ }^{a}$ Laboratoire de Chimie Physique, UMR 8000-CNRS,

Univ. Paris-Sud, 91405 Orsay, France.

E-mail: hynd.remita@u-psud.fr

${ }^{b}$ CNRS, Laboratoire de Chimie Physique, UMR 8000, 91405 Orsay,

France

${ }^{c}$ Laboratoire Charles Coulomb UMR 5221, Université Montpellier 2, 34095 Montpellier, France

${ }^{d}$ CNRS, Laboratoire Charles Coulomb UMR 5221, 34095 Montpellier, France

${ }^{e}$ Laboratoire de Réactivité de Surface, UPMC Université Paris 6 , UMR 7197-CNRS, 3 rue Galilée, 94200 Ivry, France

$\dagger$ Present address: School of Basic Sciences, Indian Institute of Technology, Mandi-175 001, Himachal Pradesh, India.
Because of the large panel of applications, synthesis of onedimensional palladium nanostructures remains a great challenge in material chemistry. But synthesis of Pd nanorods or nanowires is a relatively underexplored area when compared to that of nanorods or nanowires of other noble metals such as $\mathrm{Au}^{37,38}$ and Ag. ${ }^{39}$ Crystal structure anisotropy is believed to be the main driving force for the anisotropic growth of nanostructures. In this framework, because of its symmetric cubic lattice, $\mathrm{Pd}$ is not expected to have the propensity to grow in one direction. In addition, the kinetics control of the reduction and growth processes is critically important to control the nanoparticle size and shape and has been identified as a key factor in obtaining one- and two-dimensional Pd nanostructures in previous studies. 9,10,26,30 For example, the control of the reduction kinetics, particularly at the seeding stage, is required for the synthesis of $\mathrm{Pd}$ nanoplates ${ }^{9,26}$ or nanosheets, ${ }^{30}$ which are the results of a slow reduction process.

Various methods have been used to synthesize single Pd nanowires. Electrochemical deposition, templated or template free, was used for synthesis of palladium nanowires. ${ }^{20,40-42} \mathrm{Pd}$ nanowires have been fabricated by electrodepositing $\mathrm{Pd}$ at the step-edges on graphite, ${ }^{20,41}$ or in porous anodic aluminum oxide membranes. ${ }^{42}$ Pd nanowires have been also obtained by lithographically patterned nanowire electrodeposition ${ }^{43}$ of $\mathrm{Pd}$ on sacrificial nanoelectrodes predefined on an insulating substrate. ${ }^{44}$

In addition, submicrometer and nanosized monocrystalline $\mathrm{Pd}$ nanowires were synthesized by chemical reduction of $\mathrm{Pd}$ salts confined in polycarbonate membranes used as template. ${ }^{45}$ Ultrathin Pd nanowires with diameters of only several nanometers and of very high aspect ratio were fabricated using ultrathin Te nanowires as both reducing agent and sacrificial template in ethylene glycol. ${ }^{46}$ One-pot synthesis of palladium nanowires and nanorods was achieved hydrothermally by reduction of palladium(II) chloride using polyvinylpyrrolidone as the reductant in the presence of sodium iodide. ${ }^{47}$ We have recently reported the synthesis of palladium nanowires with controlled lengths ( $\mathrm{a}$ few tens of $\mathrm{nm}$ ) by electron beam reduction of 
palladium complexes confined in the aqueous phase of liquid crystal templates and found that the as synthesized nanowires are very active in ethanol electrooxidation. ${ }^{34}$

Surfactant mesophases have proved to be useful and versatile soft templates for the synthesis of nanostructured materials. This was first demonstrated by Attard et al. who showed the formation of direct hexagonal liquid crystals, which are composed of a mixture of a nonionic surfactant, metal salts, and water. They showed that such liquid crystals can template the synthesis of bulk porous materials and porous metal films by electro-deposition. ${ }^{48,49}$ This approach has been used to synthesize various mesoporous metals. ${ }^{50}$ On the other hand, we have shown that giant direct hexagonal mesophases made by a quaternary system (water, surfactant, cosurfactant and oil) can be used as nanoreactors to synthesize nanostructured materials both in the aqueous and in the oil phases. ${ }^{30-33,51-53}$ The mesophases are composed of oil-swollen cylinders hexagonally packed in a continuous water domain. ${ }^{54,55}$ The oil-water interface is covered by either anionic or cationic surfactants with pentanol as a cosurfactant and various nonpolar solvents (cyclohexane, toluene,...) can be used for the swelling oil. Previously reported metal nanostructures were obtained by reduction of the metal complexes in the aqueous phase of the mesophases. ${ }^{32,34,52}$

Here, we report a facile and highly selective synthesis of thin palladium nanowires of a few microns long and monodisperse in diameter, by decomposition of the metal precursor $\mathrm{Pd}_{2}(\mathrm{DBA})_{3}$ which is confined in the oil tube of the liquid crystal, using hydrazine vapour treatment. These nanowires are much longer than the ones previously synthesized by radiolysis in the confined water phase. ${ }^{34}$

\section{Experimental section}

\section{Materials}

All the high purity chemicals such as cetyltrimethylammonium bromide (CTAB) ( $\geq 98 \%$ purity), sodium dodecylsulfate (SDS) ( $\geq 99 \%$ purity), cetylpyridinium chloride (CPC) $(99 \%$ purity), tris(dibenzylideneacetone)dipalladium $(0)\left(\mathrm{Pd}_{2}(\mathrm{DBA})_{3}\right)$ (97\% purity), toluene (99.9\% purity), $\mathrm{NaCl}$ (99,5\% purity), 2-propanol ( $\geq 99.9 \%$ purity), pentanol ( $\geq 99 \%$ purity) and hydrazine hydrochloride ( $\geq 99.99 \%$ purity) were purchased from Sigma-Aldrich and were used as received.

\section{Preparation of the mesophases}

The mesophases were prepared following the previously published method $^{32-34,56}$ with some modifications. Typically, a cationic surfactant, CTAB (2.06 g), was first dissolved in $4 \mathrm{~mL}$ brine $(0.1 \mathrm{M})$ at $50{ }^{\circ} \mathrm{C}$ in Pyrex ${ }^{\mathbb{R}}$ glass tubes to get a transparent, viscous micellar solution. An opaque gel was formed by adding $6 \mathrm{~mL}$ of a solution of $\operatorname{Pd}_{2}(\mathrm{DBA})_{3}$ in toluene $\left(1.5 \times 10^{-3} \mathrm{M}\right)$ to the micellar solution and vortexing strongly the mixture. Further mixing with a few drops $(40 \mu \mathrm{L})$ of 1-pentanol yielded a transparent, gelatinous, brown coloured mesophase. The mesophases thus prepared were kept sealed and allowed to equilibrate for a few days before further experiments.

Other hexagonal mesophases were also prepared similarly with another cationic surfactant, cetylpyridinium chloride
(CPC) or with an anionic surfactant like, sodium dodecylsulfate (SDS), keeping the same concentrations of surfactant in water $(0.1 \mathrm{M})$ and of $\mathrm{Pd}_{2}(\mathrm{DBA})_{3}$ in toluene $\left(1.5 \times 10^{-3} \mathrm{M}\right)$. Note that a higher amount of cosurfactant is required to form the SDS-based and CPC-based mesophases than to form the CTAB-based mesophases. A wine red coloured hexagonal mesophase is obtained with SDS while a dark brown hexagonal mesophase is obtained with CPC as a surfactant. While solutions of the Pd-precursor $\left(\mathrm{Pd}_{2}(\mathrm{DBA})_{3}\right)$ in toluene are red as the SDSbased samples containing the precursors, samples with $\mathrm{CTAB}$ or CPC are systematically orange. The $\mathrm{Pd}(\mathrm{DBA})_{2}$ solution exhibits an absorption maximum at $520 \mathrm{~nm}$. This peak is also observed for SDS-based samples while it is absent in the case of CPC- and CTAB-based mesophases. These observations suggest that the complexes dissolved in toluene interact with CTAB and CPC but not with SDS. In the mesophases, these Pd complexes are probably located at the toluene/water interface.

Preparation of the Pd nanostructures. Pd nanoparticles were prepared using hydrazine vapour treatment. Small sample quantities (a few $\mathrm{mL}$ ) were transferred into small glass tubes with wide mouth which were placed inside a slightly bigger glass bottle containing hydrazine hydrochloride. The second bottle was kept sealed for 48 hours.

\section{Experimental techniques}

X-ray experimental setup. In order to characterize the structure of the mesophases doped with the palladium precursors, $\mathrm{X}$-ray scattering experiments were performed using an in-house setup with a rotating anode X-ray generator equipped with two parabolic mirrors giving a highly parallel beam of monochromatic $\mathrm{Cu} \mathrm{K} \alpha$ radiation (wavelength $\lambda=0.154 \mathrm{~nm}$ ). The scattered intensity is collected on a two-dimensional detector. The experimental data are corrected for the background scattering and the sample transmission. Samples were inserted in a $1.5 \mathrm{~mm}$ thick capillary (Mark-Röhrchen type from GLAS Co., Germany) and measurements were performed at a sample-detector distance $D=1 \mathrm{~m}$.

Transmission electron microscopy. After treatment with hydrazine, the mesophases were destabilized by addition of 2-propanol. The solutions thus obtained were then centrifuged to concentrate the Pd nanostructures and the supernatant was decanted. The process of addition of 2-propanol, centrifugation and decantation was repeated five times to remove the surfactant. A dilute solution of the purified nanostructure was deposited over a carbon coated copper grid for transmission electron microscopy (TEM) observations.

TEM observations were performed with a JEOL JEM 100CXII transmission electron microscope at an accelerating voltage of $100 \mathrm{kV}$ and for high resolution (HRTEM) images with a JEOL JEM 2010 at $200 \mathrm{kV}$. The chemical analyses were obtained by a selected energy-dispersive X-ray (EDX) microanalyser (PGT-IMIX-PC) attached to the JEM 2010.

\section{Results and discussion}

The Pd precursor $\mathrm{Pd}_{2}(\mathrm{DBA})_{3}$ is safe and commonly used in nanoparticle syntheses. ${ }^{30,57}$ Chaudret et al. have prepared spherical $\mathrm{Pd}$ nanoparticles from $\mathrm{Pd}_{2}(\mathrm{DBA})_{3}$ in organic solvents in the 
presence and absence of polymers such as PVP, various cellulose derivatives, hexadecylamine, carbonyl and phosphine ligands by the reaction with $\mathrm{CO} .^{58-60}$ This precursor has also been used for the synthesis of Pd nanosheets. ${ }^{30}$

Before hydrazine treatment, the CTAB-based mesophases doped with $\mathrm{Pd}_{2}(\mathrm{DBA})_{3}$ were brown, translucent and birefringent. The birefringence reveals an anisotropic structure, which was confirmed by small-angle X-ray scattering (SAXS) measurements. The SAXS spectrum (Fig. 1) exhibits the characteristic features of direct hexagonal phases with three Bragg peaks whose positions are in the ratio $1: 3^{1 / 2}: 2$ with a lattice parameter $d_{\mathrm{c}}$ of $18.9 \mathrm{~nm}$ (see the scheme in Fig. 1). The tube diameter is about $15.6 \mathrm{~nm}$.

The liquid crystal was used as a mould to synthesize palladium nanostructures. When the mesophases were exposed to hydrazine vapour, a slow and continuous change of colour of the sample occurred on the time scale of several hours. This indicated the progressive formation of the Pd nanostructures which followed the slow diffusion of hydrazine through the mesophase. After 48 hours, the mesophases turned into a black and opaque gel. The hydrazine hydrogenates the unsaturated bonds of the DBA ligand and releases $\operatorname{Pd}(0)$ which aggregates to form Pd clusters. These clusters coalesce to form Pd nanostructures.

The Pd nanostructures were easily extracted by the addition of 2-propanol and the subsequent thorough washings before mounting on carbon grids for TEM observation. Transmission electron microscopy images (Fig. 2) revealed Pd nanowires. The nanowires have a uniform diameter of 4-5 $\mathrm{nm}$ and are a few micrometers long. TEM images show that the synthesis is highly selective; only a very small amount of spherical Pd nanoparticles were observed. The selected area diffraction (SAED) obtained on a random assembly of $\mathrm{Pd}$ nanowires presents five rings that could be indexed to the fcc Pd phase (Fig. 2a, inset).

The high resolution TEM images showed that nanowires can present long monocrystalline domains (more than $30 \mathrm{~nm}$ ) with a lattice spacing of $0.228 \mathrm{~nm}$ ascribed to (111) planes of face-centered cubic (fcc) Pd, suggesting a uniform $\langle 111\rangle$ growth direction for the nanowires (Fig. 3a). They can also be composed of smaller monocrystalline domains (4-6 nm).

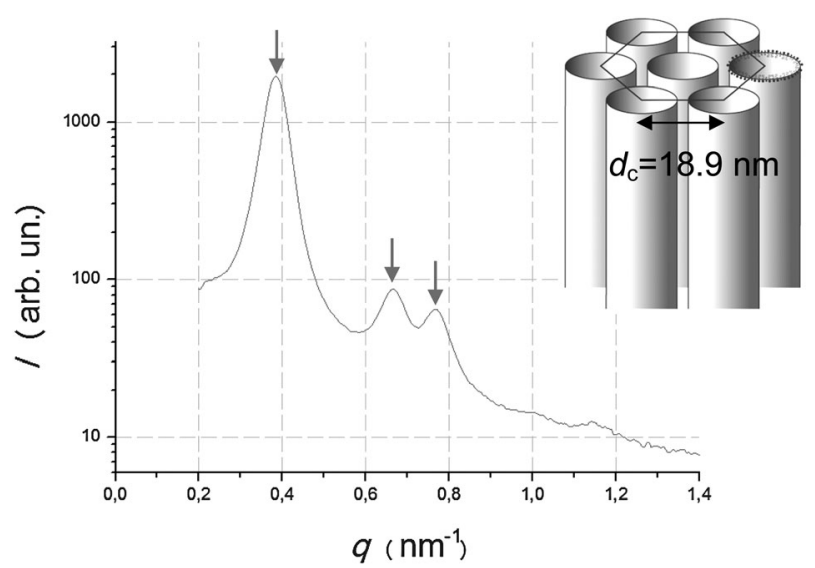

Fig. 1 SAXS spectrum of the Pd-doped hexagonal mesophase and scheme of the structure of the mesophase. The arrows point to the three main peaks.
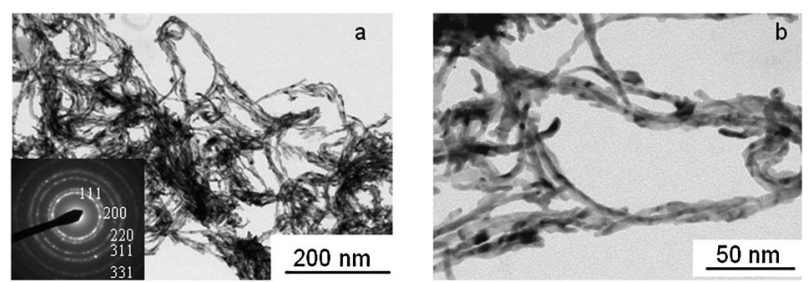

Fig. 2 (a, b) TEM images of Pd nanowires (at two different scales) prepared by hydrazine vapour treatment of a multicomponent hexagonal mesophase made of CTAB, 1-pentanol, $0.1 \mathrm{M} \mathrm{NaCl}$ in water, and $\mathrm{Pd}_{2}(\mathrm{DBA})_{3}$ complex dissolved in toluene. (a) Inset: the corresponding SAED.

The HRTEM images show a slightly disrupted growth for nanowires with kinks (Fig. 3b). The white double bars corresponding to the (111) lattice planes indicate that the nanowire continues nevertheless to crystallize along the $\langle 111\rangle$ direction (Fig. 3b). The fast Fourier transformation (FFT) confirms the weak disorientation of the (111) lattice planes within the nanowire (Fig. 3b, inset).
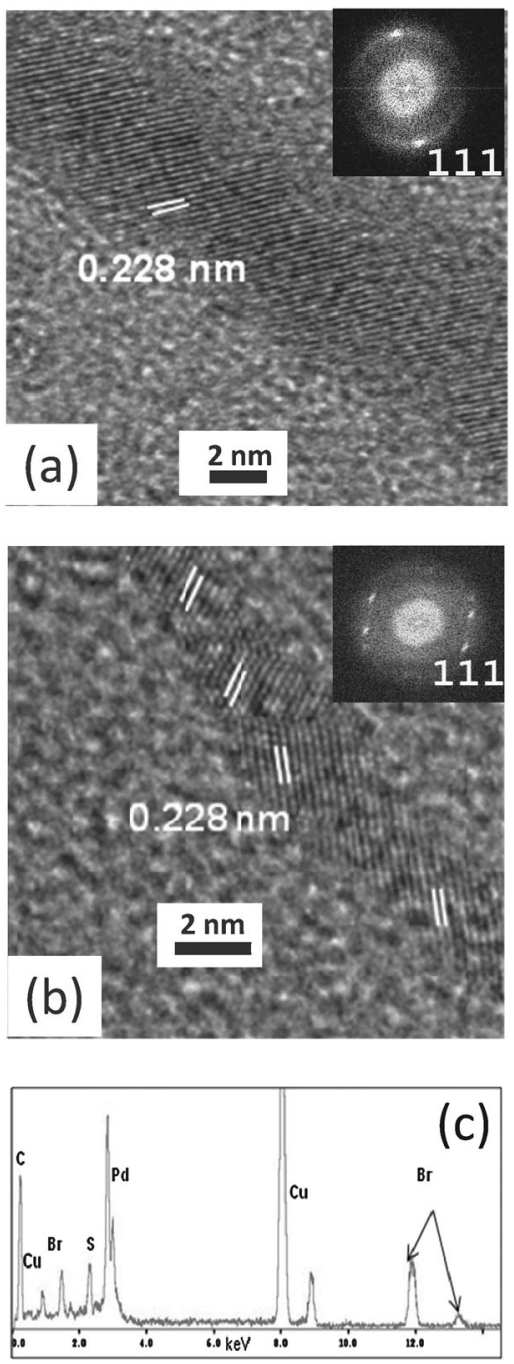

Fig. 3 HRTEM images and the corresponding FFT (inset) of (a) a $\mathrm{Pd}$ nanowire with a uniform growth direction and (b) a Pd nanowire with a disturbed growth direction. (c) EDX spectrum of the structure. 


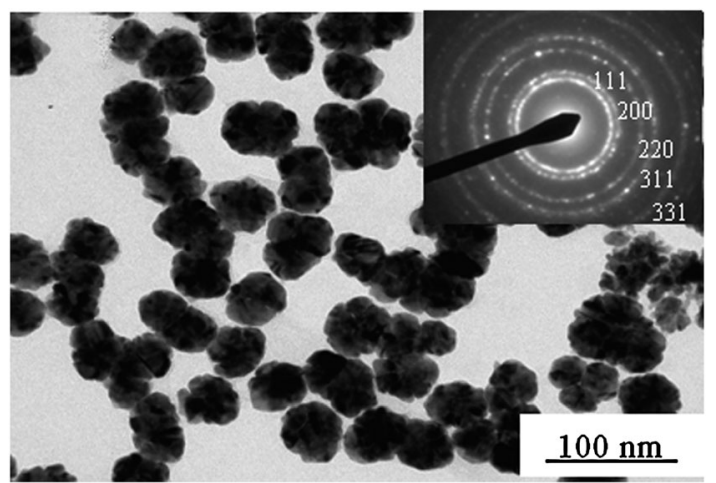

Fig. 4 Large aggregates of $\mathrm{Pd}$ formed by hydrazine vapour treatment for 6 hours of a toluene solution of $\mathrm{Pd}_{2}(\mathrm{DBA})_{3}\left(1.5 \times 10^{-3} \mathrm{M}\right)$. Inset: the corresponding SAED.

Energy dispersive X-ray spectroscopy (EDS) performed on a Pd nanowire reveals a small bromide signal, originating from the surfactant CTAB, even after several washings with 2-propanol (Fig. 3c).

As a control, a solution of $\mathrm{Pd}_{2}(\mathrm{DBA})_{3}$ in toluene $(1.5 \times$ $10^{-3} \mathrm{M}$ ) was exposed to hydrazine vapours. In this case, the reaction occurred fairly quickly as compared to when the toluene is confined in the nanometric tubes of a hexagonal mesophase, and Pd particles of fcc symmetry were observed within a short time (less than 1 hour). After 6 hours we obtained large aggregates of diameters in the range of $30-50 \mathrm{~nm}$ (Fig. 4). Longer exposure yields significantly larger aggregates that settle down at the bottom of the vials.

Experiments were also conducted in hexagonal mesophases based on SDS or CPC as surfactants. After the completion of the reaction with hydrazine (48 hours), the mesophases were black in colour. In these cases, TEM observations showed small spherical Pd nanoparticles of typical size $4-5 \mathrm{~nm}$ as shown in Fig. 5. These control experiments underline the crucial role of the CTAB surfactant.

In general, the shape of nanomaterials is highly dependent on the competitive growth rate along the low index crystal planes in the presence of surfactants. ${ }^{61-63}$ Here, the decomposition of the DBA ligand leads to unstable Pd complexes which collapse into metal clusters. These clusters presumably aggregate on the CTAB interface forming Pd nanowires. CTAB absorbs probably preferentially to the (100) facets of $\mathrm{Pd}$, inhibiting the metallic growth in the $\langle 100\rangle$ direction and facilitating the growth of the nanowires along the $\langle 111\rangle$ directions. ${ }^{20}$

Many studies have indeed shown that halides, and particularly $\mathrm{I}^{-}$and $\mathrm{Br}^{-}$adsorb tightly on clean single-crystalline $\mathrm{Pd}$ surfaces. ${ }^{64,65}$ and that $\mathrm{Br}^{-}$adsorbs preferentially on (100) facets. In this respect, the cetyltrimethylammonium bromide $\left(\mathrm{CTA}^{+}, \mathrm{Br}^{-}\right)$surfactant is considered to play a key role as a "complexing agent" and/or as a structure-directing agent through stabilization of (100) facets. The strong $\mathrm{Br}^{-}$adsorption is confirmed by the EDS spectra (Fig. 3c) obtained after several washings of the nanowires. The slow formation of the nanostructure due to the diffusion of hydrazine in the very viscous medium, as the mesophase is, probably also plays a key role in the formation of very long nanowires.
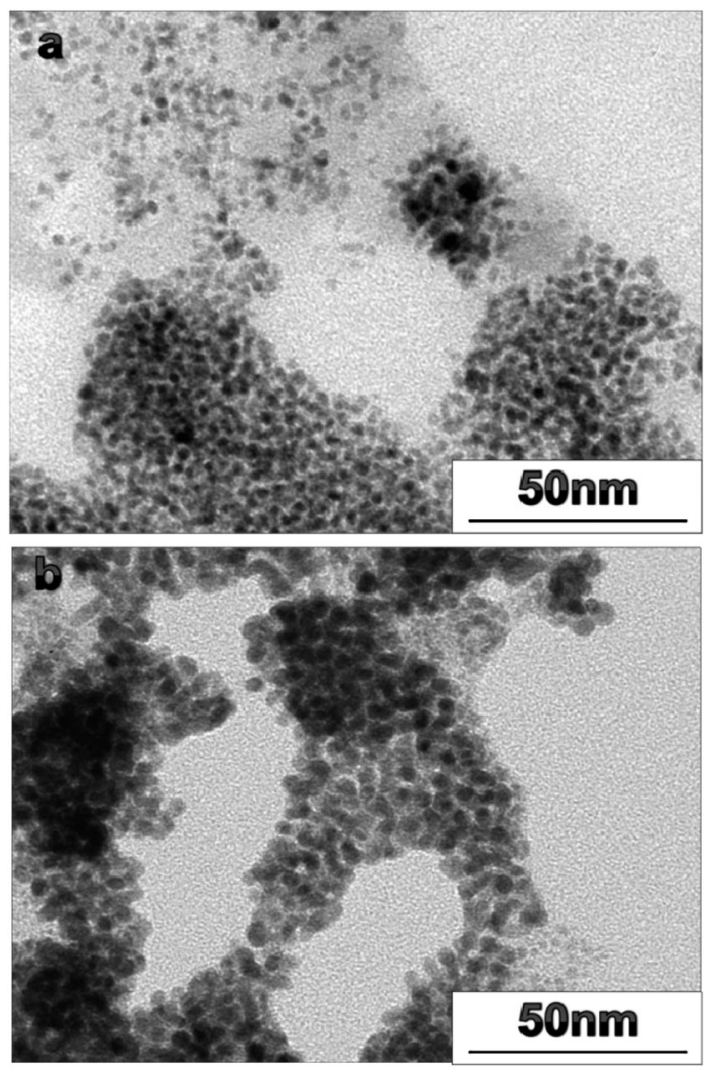

Fig. 5 TEM images of palladium nanoparticles prepared by decomposition of $\mathrm{Pd}_{2}(\mathrm{DBA})_{3}$ with hydrazine (a) in a SDS-based hexagonal mesophase and (b) in a CPC-based hexagonal mesophase.

\section{Conclusion}

In summary, we have synthesized thin Pd nanowires of very high aspect ratio and of uniform diameters $(4-5 \mathrm{~nm})$ using soft templates made by CTAB-based mesophases as nanoreactors. Our experiments show that both the confinement and the nature of the surfactant are essential to obtain Pd nanowires. CTAB plays the role of a structure-directing agent. The Pd nanowires, which can be easily extracted from the mesophase by a simple addition of 2-propanol, can have applications in catalysis, electrocatalysis and $\mathrm{H}_{2}$ sensing.

\section{Acknowledgements}

P.F.S. acknowledges the European Commission for a postdoctoral fellowship (MIF1-CT-2006-021579).

\section{References}

1 T. S. Ahmadi, Z. L. Wang, T. C. Green, A. Henglein and M. A. ElSayed, Science, 1996, 272, 1924-1925.

2 G. Berhault, L. Bisson, C. Thomazeau, C. Verdon and D. Uzio, Appl. Catal., A, 2007, 327, 32-43.

3 R. Narayanan and M. A. El-Sayed, Nano Lett., 2004, 4, 1343-1348.

4 M. Sasaki, M. Osada, N. Higashimoto, T. Yamamoto, A. Fukuoka and M. Ichikawa, J. Mol. Catal. A: Chem., 1999, 141, 223-240.

5 C. Wang, H. Daimon, Y. Lee, J. Kim and S. Sun, J. Am. Chem. Soc., 2007, 129, 6974-6975.

6 Y. Xiong and Y. Xia, Adv. Mater., 2007, 19, 3385-3391. 
7 A. Fukuoka, N. Higashimoto, Y. Sakamoto, S. Inagaki, Y. Fukushima and M. Ichikawa, Microporous Mesoporous Mater., 2001, 48, 171-179.

8 J. N. Kuhn, W. Huang, C.-K. Tsung, Y. Zhang and G. A. Somorjai, J. Am. Chem. Soc., 2008, 130, 14026-14027.

9 Y. Xia, P. Yang, Y. Sun, Y. Wu, B. Mayers, B. Gates, Y. Yin, F. Kim and H. Yan, Adv. Mater., 2003, 15, 353-389.

10 T. Redjala, H. Remita, G. Apostolecu, M. Mostafavi, C. Thomazeau and D. Uzio, Oil Gas Sci. Technol., 2006, 61, 789.

11 D. Astruc, Inorg. Chem., 2007, 46, 1884-1894.

12 Y. Li, X. M. Hong, D. M. Collard and M. A. El-Sayed, Org. Lett., 2000, 2, 2385-2388.

13 M. T. Reetz and E. Westermann, Angew. Chem., Int. Ed., 2000, 39, $165-168$.

14 S. U. Son, Y. Jang, J. Park, H. B. Na, H. M. Park, H. J. Yun, J. Lee and T. Hyeon, J. Am. Chem. Soc., 2004, 126, 5026-5027.

15 D. Astruc, Modern Arene Chemistry-Concepts, Synthesis and Applications, Wiley-VCH, 2002.

16 J. Liu, J. Ye, C. Xu, S. P. Jiang and Y. Tong, Electrochem. Commun., 2007, 9, 2334-2339.

17 N. Mackiewicz, G. Surendran, H. Remita, B. Keita, G. Zhang, L. Nadjo, A. Hagège, E. Doris and C. Mioskowski, J. Am. Chem. Soc., 2008, 130, 8110-8111.

18 S. Sen Gupta and J. Datta, J. Power Sources, 2005, 145, 124-132.

19 C. W. Xu, H. Wang, P. K. Shen and S. P. Jiang, Adv. Mater., 2007, 19, 4256-4259.

20 F. Favier, E. C. Walter, M. P. Zach, T. Benter and R. M. Penner, Science, 2001, 293, 2227-2231.

21 F. Ksar, G. K. Sharma, F. Audonnet, P. Beaunier and H. Remita, Nanotechnology, 2011, 22, 305609.

22 C. Langhammer, I. Zoric, B. Kasemo and B. M. Clemens, Nano Lett., 2007, 7, 3122-3127.

23 P. Tobiska, O. Hugon, A. Trouillet and H. Gagnaire, Sens. Actuators, B, 2001, 74, 168-172.

24 X. Q. Zeng, M. L. Latimer, Z. L. Xiao, S. Panuganti, U. Welp, W. K. Kwok and T. Xu, Nano Lett., 2011, 11, 262-268.

25 C. Koenigsmann, A. C. Santulli, E. Sutter and S. S. Wong, ACS Nano, 2011, 5, 7471-7487.

26 Y. Xiong, J. M. McLellan, J. Chen, Y. Yin, Z.-Y. Li and Y. Xia, J. Am. Chem. Soc., 2005, 127, 17118-17127.

27 Y. Sun, L. Zhang, H. Zhou, Y. Zhu, E. Sutter, Y. Ji, M. H. Rafailovich and J. C. Sokolov, Chem. Mater., 2007, 19, 2065-2070.

28 H. Meng, S. Sun, J.-P. Masse and J.-P. Dodelet, Chem. Mater., 2008, 20, 6998-7002.

29 Z. Cheng, D. Pan, H. Wang, M. Pang, Y. Han and J. Lin, Nanotechnology, 2006, 17, 506.

30 X. Huang, S. Tang, X. Mu, Y. Dai, G. Chen, Z. Zhou, F. Ruan, Z. Yang and N. Zheng, Nat. Nanotechnol., 2011, 6, 28-32.

31 P. F. Siril, L. Ramos, P. Beaunier, P. Archirel, A. Etcheberry and H. Remita, Chem. Mater., 2009, 21, 5170-5175.

32 G. Surendran, F. Ksar, L. Ramos, B. Keita, L. Nadjo, E. Prouzet, P. Beaunier, P. Dieudonné, F. Audonnet and H. Remita, J. Phys. Chem. C, 2008, 112, 10740-10744.

33 F. Ksar, L. Ramos, B. Keita, L. Nadjo, P. Beaunier and H. Remita, Chem. Mater., 2009, 21, 3677-3683.

34 F. Ksar, G. Surendran, L. Ramos, B. Keita, L. Nadjo, E. Prouzet, P. Beaunier, A. Hagège, F. Audonnet and H. Remita, Chem. Mater., 2009, 21, 1612-1617.
35 D. A. Stewart, J. Appl. Phys., 2007, 101, 09D503.

36 X. Teng, W.-Q. Han, W. Ku and M. Hücker, Angew. Chem., Int. Ed., 2008, 47, 2055-2058.

37 B. Nikoobakht and M. A. El-Sayed, Chem. Mater., 2003, 15, 1957-1962.

38 N. R. Jana, L. Gearheart and C. J. Murphy, J. Phys. Chem. B, 2001, 105, 4065-4067.

39 O. Weichold, S.-C. Hsu and M. Moller, J. Mater. Chem., 2006, 16, 4475-4479.

40 M. Z. Atashbar, V. Bliznyuk, D. Banerji and S. Singamaneni, J. Alloys Compd., 2004, 372, 107-110.

41 E. Walter, F. Favier and R. Penner, Anal. Chem., 2002, 74, 1546.

42 K. J. Jeon, J. M. Lee, E. Lee and W. Lee, Nanotechnology, 2009, 20, 135502 .

43 E. J. Menke, M. A. Thompson, C. Xiang, L. C. Yang and R. M. Penner, Nat. Mater., 2006, 5, 914-919.

44 F. Yang, D. K. Taggart and R. M. Penner, Small, 2010, 6, 1422-1429.

45 F. Yang, S.-C. Kung, M. Cheng, J. C. Hemminger and R. M. Penner, ACS Nano, 2010, 4, 5233-5244.

46 H.-W. Liang, S. Liu, J.-Y. Gong, S.-B. Wang, L. Wang and S.-H. Yu, Adv. Mater., 2009, 21, 1850-1854.

47 X. Huang and N. Zheng, J. Am. Chem. Soc., 2009, 131, 4602-4603.

48 G. S. Attard, P. N. Bartlett, N. R. B. Coleman, J. M. Elliott, J. R. Owen and J. H. Wang, Science, 1997, 278, 838-840.

49 G. S. Attard, J. M. Corker, C. G. Göltner, S. Henke and R. H. Templer, Angew. Chem., Int. Ed. Engl., 1997, 36, 1315-1317.

50 Y. Yamauchi and K. Kuroda, Chem.-Asian J., 2008, 3, 664-676.

51 E. Pena dos Santos, M. S. Tokumoto, G. Surendran, H. Remita, C. Bourgaux, P. Dieudonné, E. Prouzet and L. Ramos, Langmuir, $2005,21,4362-4369$

52 G. Surendran, M. S. Tokumoto, E. Pena dos Santos, H. Remita, L. Ramos, P. J. Kooyman, C. V. Santilli, C. Bourgaux, P. Dieudonné and E. Prouzet, Chem. Mater., 2005, 17, 1505-1514.

53 G. Surendran, G. Apostolescu, M. Tokumoto, E. Prouzet, L. Ramos, P. Beaunier, P. J. Kooyman, A. Etcheberry and H. Remita, Small, 2005, 1, 964-967.

54 L. Ramos and P. Fabre, Langmuir, 1997, 13, 682-686.

55 L. Ramos, P. Fabre and R. Ober, Eur. Phys. J. B, 1998, 1, 319-3326.

56 G. Surendran, L. Ramos, B. Pansu, E. Prouzet, P. Beaunier, F. Audonnet and H. Remita, Chem. Mater., 2007, 19, 5045-5048.

57 S. Franzen, J. Chem. Educ., 2011, 88, 619-623.

58 C. Amiens, D. de Caro, B. Chaudret, J. S. Bradley, R. Mazel and C. Roucau, J. Am. Chem. Soc., 1993, 115, 11638-11639.

59 A. Duteil, R. Queau, B. Chaudret, R. Mazel, C. Roucau and J. S. Bradley, Chem. Mater., 1993, 5, 341-347.

60 E. Ramirez, S. Jansat, K. Philippot, P. Lecante, M. Gomez, A. M. Masdeu-Bulto and B. Chaudret, J. Organomet. Chem., 2004, 689, 4601-4610.

61 Z. L. Wang, J. Phys. Chem. B, 2000, 104, 1153-1175.

62 Y. Xia and N. J. Halas, MRS Bull., 2005, 30, 338-348.

63 J. Chen, B. J. Wiley and Y. Xia, Langmuir, 2007, 23, 4120-4129.

64 M. P. Soriaga, J. A. Schimpf, A. Carrasquillo Jr, J. B. Abreu, W. Temesghen, R. J. Barriga, J. J. Jeng, K. Sashikata and K. Itaya, Surf. Sci., 1995, 335, 273-280.

65 A. J. Carrasquillo, J.-J. Jeng, R. J. Barriga, W. F. Temesghen and M. P. Soriaga, Inorg. Chim. Acta, 1997, 255, 249-254. 